This item was submitted to Loughborough's Research Repository by the author.

Items in Figshare are protected by copyright, with all rights reserved, unless otherwise indicated.

\title{
Design of a STEP compliant system for turning operations
}

PLEASE CITE THE PUBLISHED VERSION

http://dx.doi.org/10.1016/j.rcim.2010.05.002

PUBLISHER

(c) Elsevier Ltd.

VERSION

AM (Accepted Manuscript)

LICENCE

CC BY-NC-ND 4.0

REPOSITORY RECORD

Yusof, Yusri, and Keith Case. 2019. "Design of a STEP Compliant System for Turning Operations". figshare. https://hdl.handle.net/2134/11039. 
This item was submitted to Loughborough's Institutional Repository (https://dspace.lboro.ac.uk/) by the author and is made available under the following Creative Commons Licence conditions.

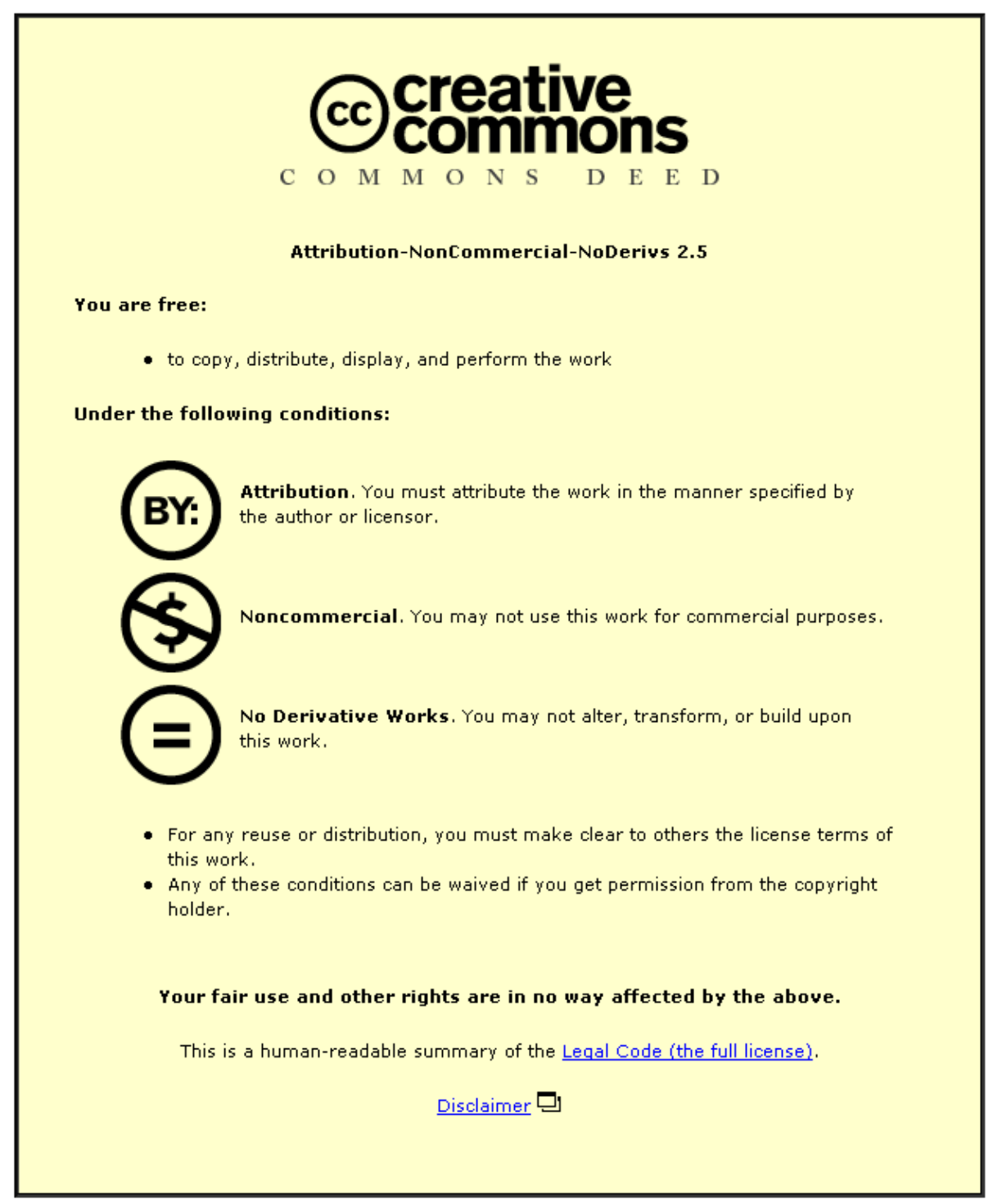

For the full text of this licence, please go to: http://creativecommons.org/licenses/by-nc-nd/2.5/ 
Journal of Robotics and Computer-Integrated Manufacturing

Vol. 26, No. 6, pp753-758, 2010

\title{
Design of a STEP compliant system for turning operations
}

\author{
Yusri Yusof ${ }^{1,2}$, Keith Case ${ }^{2}$ \\ 1 Faculty of Mechanical and Manufacturing Engineering, Universiti Tun Hussein Onn \\ Malaysia Johor (UTHM), Parit Raja, 86400 Batu Pahat, Johor, Malaysia \\ 2 Mechanical and Manufacturing Engineering, Loughborough University, Loughborough \\ LE11 3TU, United Kingdom
}

\begin{abstract}
The changing economic climate has made global manufacturing a growing necessity over the last decade, forcing companies from East and West to collaborate beyond geographic boundaries in the design, manufacture and assembly of products. The ISO 10303 and ISO 14649 Standards (STEP and STEP-NC) have been developed to introduce interoperability into manufacturing enterprises so as to meet the challenges of responding to production on demand. This paper describes and illustrates a STEP compliant CAD/CAPP/CAM System for the manufacture of rotational parts on CNC turning centers. The information models to support the proposed system together with the data models defined in the ISO 14649 standard used to create the NC programs are also described. A structured view of a STEP compliant CAD/CAPP/CAM system framework supporting the next generation of intelligent CNC controllers for turn/mill component manufacture is provided. Finally a proposed computational environment for a STEP-NC compliant system for turning operations (SCSTO) is described. SCSTO is the experimental aspect of the research and is supported by information models that and have been constructed using a structured methodology and object-oriented methods. SCSTO was developed to generate a Part 21 file based on machining features to support the interactive generation of process plans utilizing feature extraction. A case study component has been developed to prove the concept of using the milling and turning parts of ISO 14649 to provide a turn-mill CAD/CAPP/CAM environment.
\end{abstract}

\section{Introduction}

Today, with the use of computer and communication technologies in manufacturing industry, manual and semi-automatic methods have largely being replaced by computer aided design (CAD) and computer aided manufacturing (CAM) to implement concurrent engineering [1]. Widespread CADCAM systems with reduced human interaction should result in increased production, reduced costs and better quality of product. Modern CNC machines utilize a variety of cutting technologies including multi-turrets and multi-spindles in various axial configurations increasing the level of complexity compared with machines of 
previous decades [2]. A large number of CAx systems have been developed and implemented in recent years to provide computer support to many stages of product life and many of these can simulate virtual CNC machining with the complete machine toolpath [3]. Most of these systems are specialized to support certain applications and are based on an information model that handles the application specific view of the product. These CAx systems do not share common databases for the product information.

Since the first NC machine was introduced in 1947, various process planning packages have been developed and each new system attempted to interpret the part data more reliably. To date there are more than 2000 varieties of CNC machine-controller combinations around the globe, leading to the need for a single standard to improve productivity by increasing the richness of interactions and transactions. An initial standard is ISO 10303, informally known as the STandard for the Exchange of Product (STEP) data, which aims to provide a single International Standard for all technical aspects of products [4].

This paper presents an overall review of the various research projects carried out by the major research groups in this area. The relevant research issues for the development and introduction of reconfigurable machines tools are presented focused on turning operations. Finally, the authors propose a STEP-NC compliant CAD/CAPP/CAM system that is currently being implemented at Bath University, UK and UTHM, Malaysia. A case study based on a component from industry is used to demonstrate the capabilities of the system.

\section{Review of STEP-compliant manufacturing}

Over the last 15 years many efforts have been made to apply STEP concepts to the data interface between CAD/CAM and CNC. The use of ISO 6983 (G\&M codes) for programming CNC machines requires NC part programs to be specific to a machine and CNC controller. This is particularly true for the programming of asymmetric rotational parts that can be manufactured on a wide variety of turn/mill centers. Through considering new standards, such as ISO 14649, this research explores the opportunities for using STEP-NC part programs on different turning centre configurations so as to provide a platform for interoperable manufacture. Both standards can be summarized as shown in Fig. 1. To satisfy the latest requirements and demands with respect to bi- directional process chains of machining modeling, several different technology-specific process models are necessary within STEP-NC. A new data interface framework for the milling process has been proposed in the OPTIMAL project to overcome the legacy standards of ISO 6983, informally known as "G codes" [5]. This is one of the earliest STEP-compliant systems and is based on feature information and machining strategies. The research does not stop there, because the researchers are now focusing on identifying and defining interoperable manufacturing and STEP-NC compliance in the context of concurrent engineering. In particular, their information review of Standards for the Exchange of Product Model Data for Numerical Controls (STEP-NC), manufacturing processes and manufacturing resources provides the basis for this paper. STEP- NC has been developed as a result of several research projects carried out by companies and academic institutions.

Standardization and application are two identifiable STEP compliance research topics. In standards activities project names such as ISO, NIST, NCMS, ESPRIT Project and IMS are recognized around the world [6, 7]. On the other hand for STEP compliant applications, STEP Tool (USA), WZL RWTH-Aachen and ISW Stuttgart University (Germany), the 
National Research Laboratory for STEP-NC Technology (NRL-SNT), the University of Bath and the University of Auckland are among the established research groups [8].

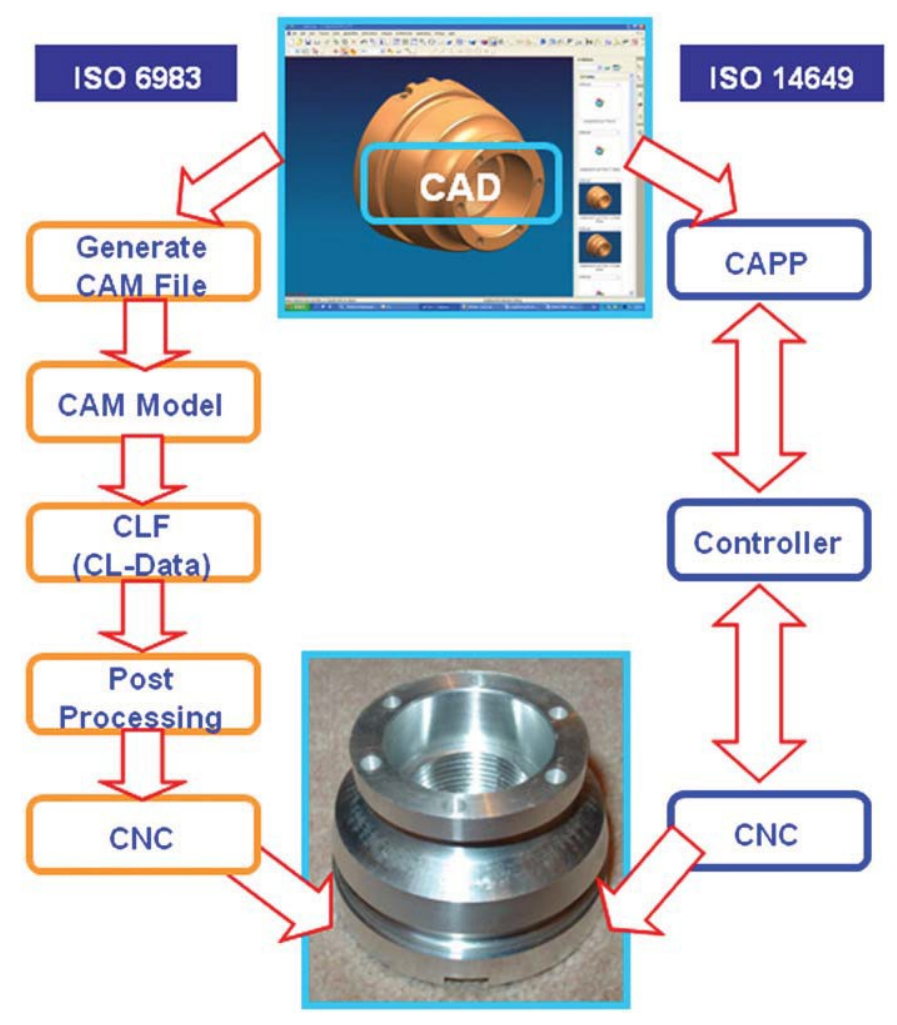

Fig. 1. Comparison of the CAD/CAPP/CAM process chain with ISO 6983 and ISO 14649.

$\mathrm{Xu}$ et al. [6] have provided an overall view of the various research projects carried out by the major research groups worldwide in the application of STEP-NC for CAD, CAPP, CAM and CNC integration. They review the major global endeavors in STEP-NC related research projects including IMS STEP-NC, European ESPRIT STEP-NC, Super Model, STEP Manufacturing Suite (SMS), Rapid Acquisition of Manufactured Parts (RAMP) and Intelligent manufacture for STEP-NC-compliant machining and inspection. Other important aspects that are discussed concern work that has been carried out by research groups from countries such as Germany, Switzerland, UK, Korea, USA and New Zealand. One of the aim for the next generation CNC machines is to be portable, interoperable and adaptable so that they can respond quickly to changes in market demand and the manufacturing needs of customized products and this is agreement with the STEP-NC manufacturing roadmap suggested by Suh and Lee [9]. The roadmap consists of three steps to consider for the STEPManufacturing environment: (1) participation with many manufacturing-related companies, (2) movement towards an information-oriented and international environment and finally, (3) consideration of compact and economical research and development [10]. The year 2006 was a time when researchers were extremely focused on this particular area and details can be found a special issue edition of IJCIM for STEP-Compliant Process Planning and Manufacturing. Most of the researchers proposed a system framework to support data interoperability between the various CAx systems based on ISO standard 14649 that provided the first data exchange format used in the operation of NC machines. This 
development of a future manufacturing platform to enable different process models to be integrated for the adaptable integration of CAD/CAPP/CAM and CNC will be a major avenue of research for years to come.

\section{Proposed STEP compliant system for turning operations (SCSTO)}

A STEP-NC compliant CAD/CAPP/CAM prototype system for turn/mill operations is being developed to consider the complexity of turning centre configurations and is based on STEP-NC turning features [11]. This prototype system (SCSTO) has been built using JBuilder 2005 and the JDataStore database. Tasks and major functions are divided into definition of the: (i) workpiece, (ii) manufacturing features, (iii) turn/mill operations, (iv) project set-up, (v) function/technology, (vi) manufacturing strategies, (vii) placements/lengths and (viii) tools [12].

\subsection{Turning classes}

The process data for turning is provided in ISO 14649 Part 12 [13], which specifies the technology specific data elements that are needed as process data for turning [2]. Part 10 describes the general process data [8]. Included in Part 12 are features and operation data models for conventional turning, involving $\mathrm{X}$ and $\mathrm{Z}$ axis movements. This again only

represents the standard rotational turning with no representation of features and operations for composite machining such as C-axis milling operations. Fig. 2 shows example turning classes based on ISO 14649. This system needs integrated manufacturing information about the product model and manufacturing resources, and is also based on an object-oriented platform. Another aspect of information is the description of the manufacturing process, and the product geometry that can be created and manipulated. The structured model approach in the STEP-NC manufacturing chain starts with the definition of feature-based design geometry in a CAD/CAM system. An ISO 10303 Part 21 physical file is then generated from 


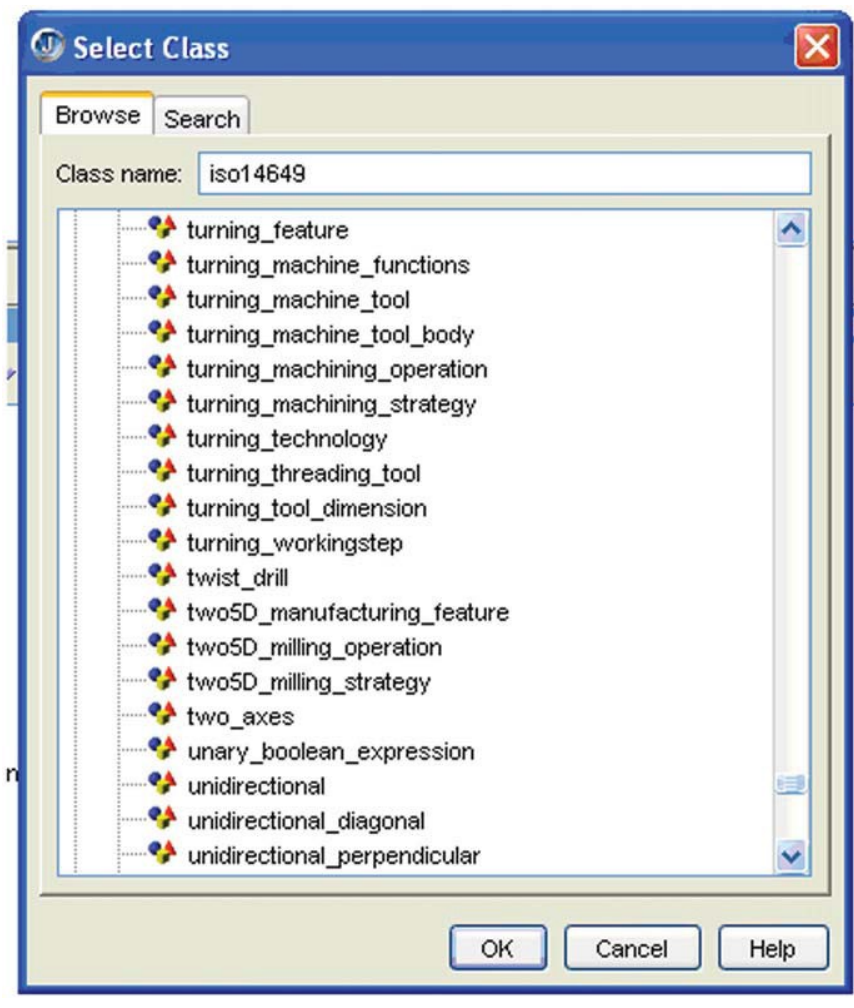

Fig. 2. Turning classes based on ISO 14649.

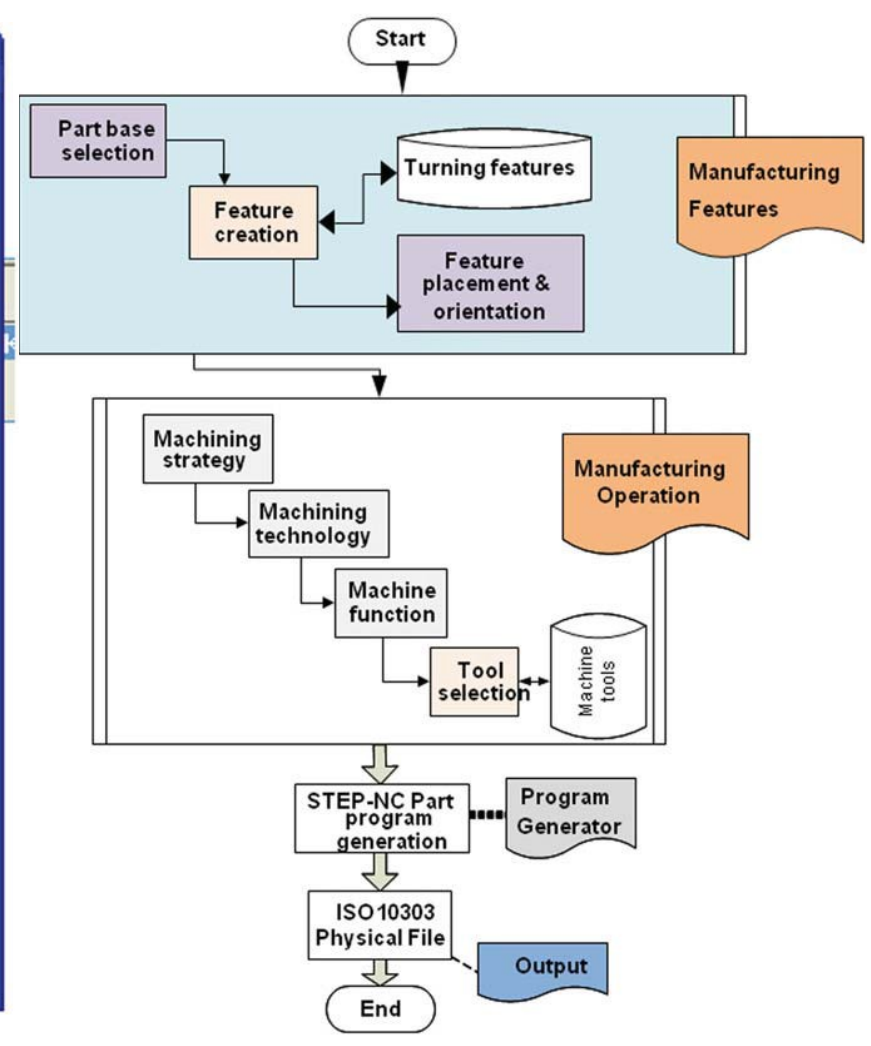

Fig. 3. Operational structure of SCSTO.

a STEP-NC compliant CAPP/CAM system based on a suite of Java information classes from the STEP-NC ARM model definition, developed by the authors. The operator is able to define STEP-NC features and is prompted for associated manufacturing inputs such as workingsteps, operations, tools, feeds and speeds consistent with the STEP-NC ISO 14649 Part 12 and 121 standards. The ISO 10303 Part 21 physical file is automatically generated. This file is processed by the STEP-NC translator (developed by ISW, Stuttgart and Siemens) and is converted into the Siemens ShopTurn CAM software proprietary format .MPF file [2]. The generated file can then be directly machined on any CNC workstation equipped with a Siemens controller and ShopTurn CAM software.

\subsection{Information model}

The implementation of SCSTO consists of three main stages: the representation of the information model, the development of the tool database and the construction of the system application as shown in Fig. 3 [14]. The first stage includes the system framework for SCSTO using an information model derived from the STEP-NC standards. The framework is described mainly from the information and functional perspectives of the CAD to CNC process chain. The information model was established by Molina [15] and consists of a product model and a manufacturing model. The product model represents relevant information about the product throughout its life cycle while the manufacturing model is defined as an information model that identifies information describing the manufacturing resources, processes and strategies. The system has been modeled using the unified modeling 
language (UML) that clearly shows the system information model in terms of classes, attributes, relationships and operations. Various objects in the SCSTO environment and each of the entities is based on ISO 14649 Parts 10, 11, 12, 111 and 121 [13, 16-19] The class diagram depicting various classes of product and process data types was created using Rational Rose version 2000. The second stage in constructing SCSTO is the database system developed using JDataStore. In SCSTO the cutting-tools database involves both turning and milling tools.

\subsection{Turning operations}

Turning schema, definitions of technology specific data types representing machining features and processes for turning operation on lathes, are defined with reference to the ISO standard [13]. The turning operation has two basic categories of machining operation either roughing or finishing. All the turning operations are part of the machining_operation subclass which is based on the operation class. In turning the workingsteps include manufacturing features and machining operations which are defined by turning_feature and turning_operations, respectively. The UML representation was developed for the diagrams, the constraints and the extension mechanisms. UML is the most widely known and used standardized notation for object-oriented analysis and design. The most useful standard UML diagrams are those for use case, class, sequence, state chart, activity, component and deployment. For the purposes of this research only class diagrams and their notation were used. The UML diagram represents the various objects in the turning manufacturing environment and the relationships between these objects. Each data type in these models is based on ISO 14649 Part 10 and Part 12 [12, 13]. A class diagram illustrates how the object identifies itself through a set package of ISO 14649 for manufacturing features consisting of fields, constructors and methods using a Java programming approach. The Java programming language was used for the development of software components based on an object-oriented methodology and UML was utilized as the modeling language.

\subsection{Graphic user interface (GUI)}

The operational structure of SCSTO is related to the programming procedure to enable rapid generation of a Part 21 File. The SCSTO system adheres to the Windows standard for user interface design. All functions can be accessed from the pull-down menus, and common functions are accessible via toolbar icons. It mainly seeks inputs from the system users via dialogs, either by selecting from standard data or keys in dialogs. The process begins with defined turning features; turning operations, turning strategies, tooling and code generation. The user can also define their own data or edit and modify their own data. The project dialog is the first dialog that appears on the screen when a new project is created and this is the starting point of the data input process. This dialog continues with a link to the workpiece dialog and workplan dialog according to the SCSTO scheme by selecting the various options featured in a java combo box. After workpiece and workplan entity entry have taken place, the next entity considered is the turning feature. Fig. 4 illustrates the turning_machine_strategy dialog depicting the various attributes of the turning strategy entity. 


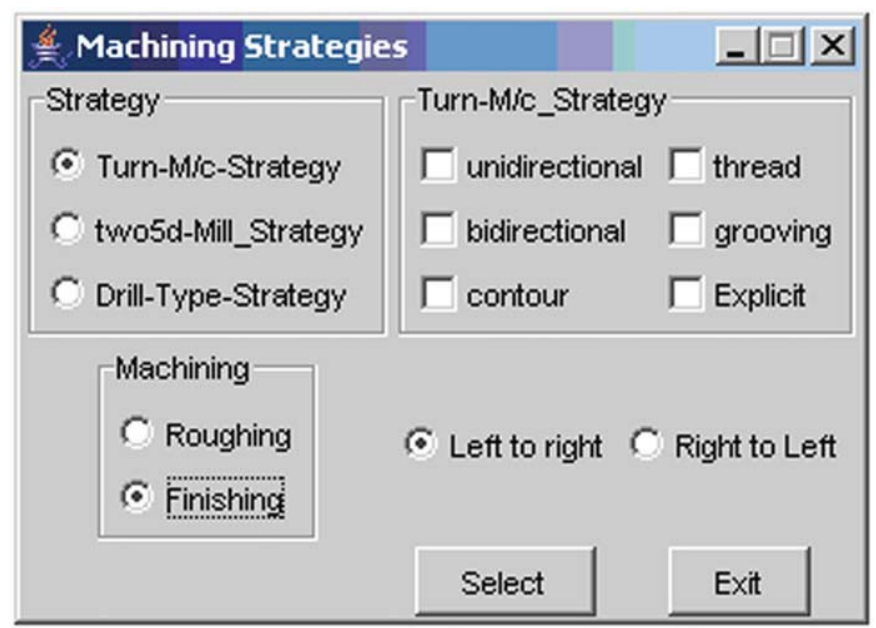

Fig. 4. Turning machining strategy dialog.

SCSTO is based on STEP feature-based design and it defines part data in terms of machining features and their technical attributes based on STEP-224. After creating the base part, the feature attachment process can be started. The designer can start with any feature depending on his/her design for manufacturing intent. Feature selection is done by clicking the "manufacturing feature"' button and a pop up window will be displayed. Illustrations in this dialog help the user to get some idea of the machining strategy chosen. Next, the machining workingsteps, which are characterized by the turning_machining_operation, define all the machining operations and technology specific data needed to define a turning operation. The data are captured via manufacturing operations, machining strategies, turning technology and the machine function dialogs. The output of SCSTO is a text file that is compliant with the ISO 10303-21 physical file format. The overall structure of SCSTO including the output STEP file is illustrated in Fig. 5.

\section{Case study component}

An industrially oriented case study component representing a selection of operations and features has been used to illustrate and demonstrate the system [12]. The case study component was adapted from component photographs in the Mazatrol brochure. The component provides an understanding of a wide variety of inner and outer features and their orientations that can be used in the design of rotational components. The overall size for the component is $170 \mathrm{~mm} \times \varnothing 70 \mathrm{~mm}$. These dimensions are given considering the feature geometric attributes and absolute placement considering machining and tool aspects. Each feature of the component is labeled and the machining operations used are turning, grooving and drilling. The component consists of turning features defined in STEP terminology as: out diameter to shoulder, revolved flat, revolved round, grooves, thread and milling features such as the revolved surface of the component. The constituent features of the component are shown in Fig. 6 where the features are not arranged in any particular hierarchy. The main reason for choosing this component is that it provides an introduction to the addition of 
milled features. This configuration represents the first level of turn/mill CNC turning for just the $\mathrm{X}, \mathrm{Z}$ and $\mathrm{C}$ axes as found for example in the Okuma and Homa model HL35M. The requirements on the machining process in this case are that the

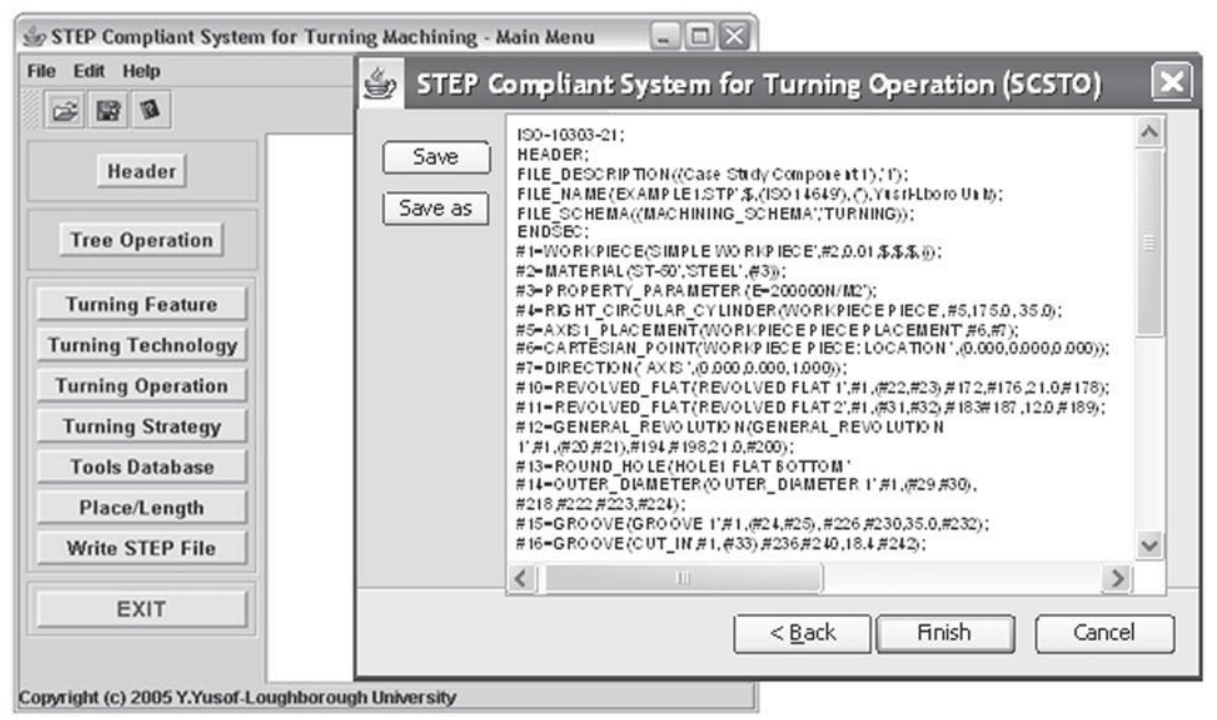

Fig. 5. The SCSTO prototype.

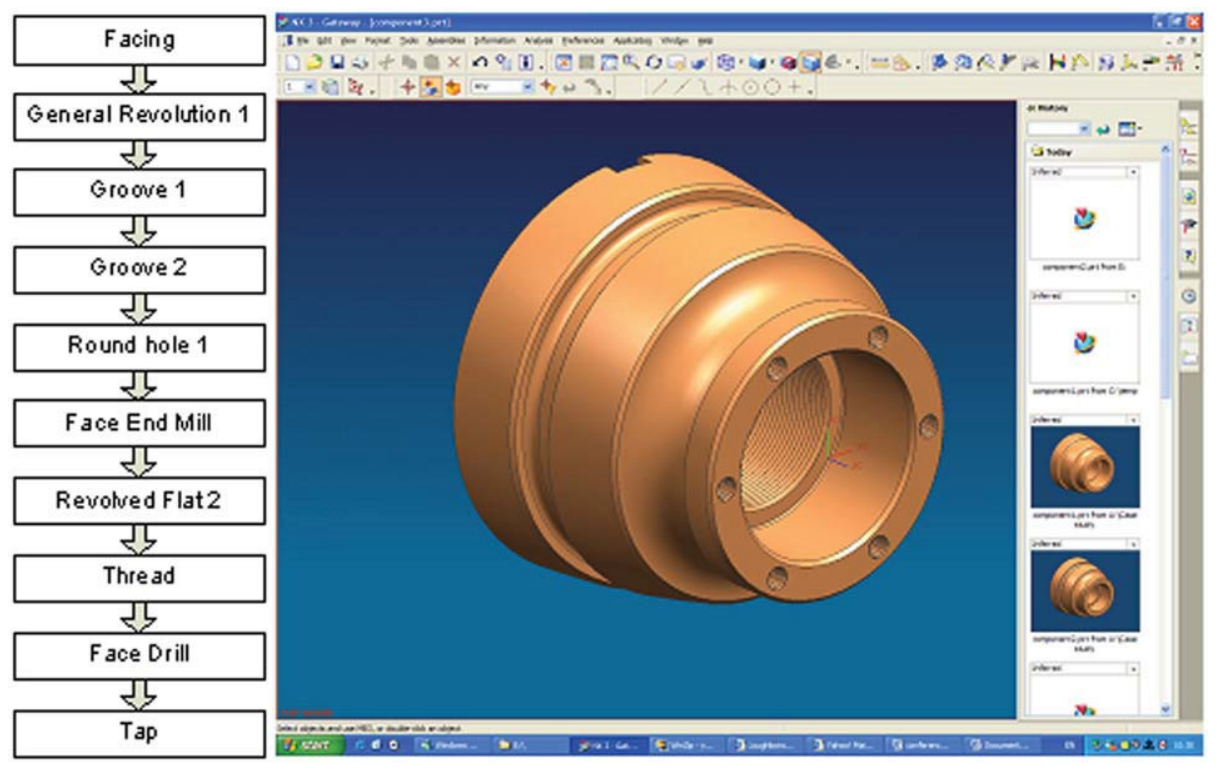

Fig. 6. Turning centre configuration for case study component.

tool-paths shall be, as far as possible, continuous and with few direction changes to prevent marks on the surfaces. The input to SCSTO consists of the geometrical parameters of the workpiece and its features and the operations plan for this particular component consists of some 37 NC-sequences. The system generates workingsteps and a workplan, building a tree structure that has a feature linked with those already defined in turning operations. Turning workingsteps are a list of turning features that are machined in sequence using the turning operations. The workplan follows primarily the setups as defined in the early stages of the process plan. 
Finally, an ISO 14649 part program is generated by clicking the Generate Code button. The program is based on textual representations of the workpiece and machining_workingsteps in a physical file. This part program is based on manufacturing features, strategies, tools, etc. and can be edited by the user and when finalized can be sent to the machine controller.

This case study has described a prototype system to validate the functioning of SCSTO and has demonstrated the capability of assisting in generating process plans for turning operations with geometry either defined by users or generated from an AP 203 CAD file. The case study has shown this prototype system can work either by the user creating features or by importing features from a CAD file. Overall it has been shown that this prototype system functions appropriately to generate a part program compliant with ISO 14649.

Milling operations are allowed on the side and face of the component. Parts requiring a second set-up are manually rotated and positioned and re-held in the chuck in relation to first set-up unless the machine is provided with a counter spindle to allow machining of the other side with a single set-up. The overall range of configurations for turning centers capable of machining this component includes machines with between 2 and 5 axes. The machining operations for this case study component consist of turning, grooving, threading, off centre drilling and milling on the side face. In terms of general attributes the component is doublesided asymmetrical. The final component is shown in Fig. 7.

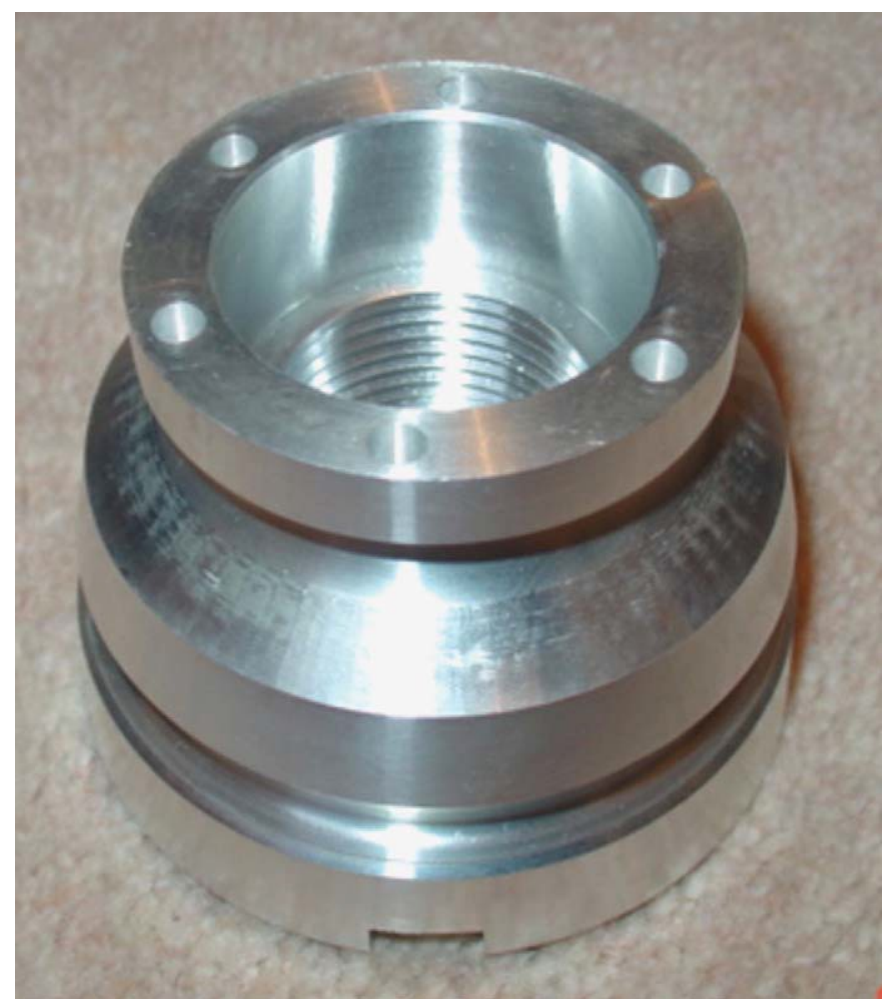

Fig. 7. Case study component.

\section{Conclusion}

This paper has outlined current CAPP and CAM systems related to STEP-NC that have been created by other worldwide researchers and illustrated the proposed STEP-NC 
compliant CAD/ CAPP/CAM system that is currently being implemented by the authors.

This research work was motivated by industrial requirements of concurrent engineering, standard product data models and an integrated manufacturing environment, which are further reflected in process planning. The information modeling in this area addresses the problems of capturing and representing manufacturing information related to resources and processes. The interaction between the different types of models could provide a description of the products, how they should be manufactured, and what manufacturing resources should be used. This would provide an information platform upon which several different computerbased tools to support the innovation process can be built. This will allow the provision of reliable manufacturing information to assist in the execution of product development life cycle activities and related decisions. SCSTO was developed to generate a Part 21 file based on machining features to support the interactive generation of process plans utilizing feature extraction. The system was constructed using a structured methodology for its planning and object-oriented methods for its implementation. A case study component was tested to show that the new approach (STEP-NC) can generate code which is comparable to the currently used G-code with some benefits such as the elimination of the post-processor. Efforts are underway to fulfill the STEP-NC challenge by combining Parts 11 and 12, for turn/mill operations. STEP-NC forms a possible basis to satisfy the latest requirements and demands with respect to a bi- directional CAx process chain for machining. In addition its development as a future manufacturing platform to enable different process models to be integrated for the adaptable integration of CAD/CAPP/CAM and CNC will be a major avenue of research for years to come. It is expected that the recommended future extensions will enhance the usefulness of this work, and will meet the requirements for global interoperable manufacturing for real-life parts. There is no doubt that, so far, none of the proposed systems are fully capable of machining turn/mill components. Work to date has focused on the separate parts of ISO 14649 using Part 11 for milling operations including drilling and Part 12 for turning. No significant work has been done on combining the two parts for turn/mill components. However, the authors believe that this industrial requirement could be achieved through research and development involving collaboration by researchers, users, manufacturers, academia and the ISO committee.

\section{Acknowledgements}

This work was supported in part by the Malaysia Government under Science Fund Grant S010, University of Tun Hussein Onn Malaysia (UTHM), Loughborough University and University of Bath. 


\section{References}

[1] Newman ST, Nassehi A, Xu XW, Rosso Jr. RSU, Wang L, Yusof Y. et al. Strategic advantages of interoperability for global manufacturing using CNC technology. Robotics and Computer-Integrated Manufacturing 2008; 24:699-708.

[2] A. Nassehi, R.D. Allen, S.T. Newman, Intelligent replication of manufacturing information between CAD/CAM systems and CNC controllers. In: Proceedings of the 16 th international conference on flexible automation and intelligent manufacturing conference (FAIM2006), Limerick, Ireland, June 2006. p. 413-420.

[3] Newman S. Integrated manufacture for the 21st century Development of the STEP-NC standard and its implications for manufacturing processes world- wide. Metalworking Production 2004; 148:13-6.

[4] ISO, International Organization for Standardization-ISO 10303-1:1994, part 1: overview and fundamental principles. Product data representation and exchange, 1994.

[5] ESPRIT, Project 8643, Optimized preparation of manufacturing information with multilevel CAM-CNC coupling (OPTIMAL): final report for publication, 1997.

[6] Xu XW, Wang H, Mao J, Newman ST, Kramer TR, Proctor FM, et al. STEP-compliant NC Research: the search for Intelligent CAD/CAPP/CAM/ CNC integration. International Journal of Production Research 2005; 43:3703-43.

[7] Xu X, Newman ST. Making CNC machine tools more open, interoperable and intelligent. Computers in Industry 2006; 57:141-52.

[8] Xu XW, He Q. Striving for a total integration of CAD, CAPP, CAM and CNC. Robotics and Computer-Integrated Manufacturing 2004; 20:101-9.

[9] S.-H. Suh, B.E. Lee. STEP-Manufacturing roadmap. In: Proceedings of the 2004 society of CAD/CAM engineers, Kangwon, Korea, 2004.

[10] Suh S-H, Chung D-H, Lee B-E, Shin S, Choi I, Kim K-M. STEP-compliant CNC system for turning: data model, architecture, and implementation. Computer-Aided Design 2006; 38:677-88.

[11] Y. Yusof, R.S.U. Rosso-Jr, S.T. Newman, K. Case. The design of a STEP-NC compliant CAD/CAPP/CAM system for the manufacture of rotational parts on a CNC turning centre. In: Proceedings of the 23rd international manufacturing conference (IMC23), University of Ulster, Northern Ireland, UK, 2006. p. 19-28.

[12] Y. Yusof, K. Case, S.T. Newman, X.W. Xu.. A STEP compliant system for turning operations. In: Proceedings of the 17th international conference on flexible automation and intelligent manufacturing (2007 FAIM), Philadelphia, USA, 2007. p. 140-147.

[13] ISO, International Standard 14649-12: part 12: industrial automation system and integration - physical device control - data model for computerized numerical controllers - part 12: Process data for turning, 2005.

[14] Yusof Y, Case K. A STEP Compliant Approach to Turning Operations. In: Xu X, Nee AYC, editors. Advanced Design and Manufacturing Based on STEP. Springer; 2009. p. 105-24.

[15] G. Molina, A manufacturing model to support data driven applications for design and manufacture, Manufacturing Engineering Loughborough: Loughborough University, 1995. p. 330.

[16] ISO, International Standard 14649-10: part 10: industrial automation system and integration - physical device control - data model for computerized numerical controllers - part 10: general process data, 2004.

[17] ISO, International Standard 14649-11: part 11: industrial automation system and integration - physical device control - data model for computerized numerical controllers - part 11: process data for milling, 2004. 
[18] ISO/FDIS, Industrial automation systems and integration - physical device control - data model for computerized numerical controllers - part 111: tools for milling machines, 2004.

[19] ISO, International Standard 14649-121: part 121: industrial automation system and integration - physical device control - data model for computerized numerical controllers - part 121: tools for turning Machines, 2005. 